\title{
The Role of Students' Worldview on Decision-Making: An Indonesian Case Study by a Socio-Scientific Issue-Based Instruction Through Integrated STEM Education
}

\author{
Bevo Wahono ${ }^{1 *}$, Erlia Narulita ${ }^{1}$, Chun-Yen Chang ${ }^{2}$, Ericka Darmawan ${ }^{3}$, Irwanto Irwanto ${ }^{4}$ \\ ${ }^{1}$ Faculty of Teacher Training and Education, University of Jember, INDONESIA \\ 2 Science Education Center, National Taiwan Normal University, TAIWAN \\ ${ }^{3}$ Faculty of Education, University of Tidar, INDONESIA \\ ${ }^{4}$ Department of Chemistry Education, State University of Jakarta, INDONESIA
}

Received 3 July 2021 - Accepted 2 September 2021

\begin{abstract}
This study aims to determine the role of worldview perspective on science students' decisionmaking process by a socio-scientific issue-based instruction through an integrated Science Technology Engineering and Mathematics (STEM) education. Understanding the decision-making process in complex themed learning is one of the most important instruments in understanding the way students think. The participants were one hundred and nine junior-high-school students from two different schools. Furthermore, the method used was a pre-experimental design with two collective groups, namely the pre-and posttest, starting with an educational study design. The results showed that there was a different perspective pattern based on the worldview perspective on students' initial decisions. Furthermore, interventions with socio-scientific issues (SSI) based instruction through integrated STEM education provided significant dynamics of change in the final science decision made by the students on the basis of a worldview perspective and gender. Some practical implications were extremely discussed, such as the crucial role of the teacher during a complex lesson topic. Therefore, this study makes an indispensable contribution to the development of the knowledge of science teaching practice, especially on how a decision-making process occurs by a socio-scientific issue-based instruction through integrated STEM education.
\end{abstract}

Keywords: decision-making, science learning, socio-scientific issue, STEM education, worldview

\section{INTRODUCTION}

Particularly, Indonesia is a country known for its strong culture and religion. All activities of its community life, including in the education field, are closely related to these two values (Lie, 2015; Wahono \& Chang, 2019). Therefore, it is not surprising that topics on science and technology are always accompanied and linked to the discussion with the norms and values prevailing in Indonesia's culture and religion. This situation has made several potential topics controversial (Subiantoro, 2017), one of which is genetically modified organisms (GMOs). Indeed, it is somehow taboo to modify living things or their body part in the Indonesian context. Likewise, in a general context, Petousi and Sifaki
(2020) argue that a condition of losing trust in the science due to any research misconduct potentially emerges some socio-scientific issues in the global society. Consequently, it is vital and exciting to have an in-depth discussion on how the value-based views held by students affect the science decision-making process in the classroom. Furthermore, on how the initial knowledge influenced by culture and religion is organized and becomes the basis for their scientific considerations, especially in dilemma learning settings (e.g., socio-scientific issue).

One of the most critical instruments required to understand how students think is to become acquainted with the decision-making process in complex themed learning, such as the socio-scientific issue (Leung, 2021).

(c) 2021 by the authors; licensee Modestum. This article is an open access article distributed under the terms and conditions of the Creative Commons Attribution License (http://creativecommons.org/licenses/by/4.0/). 


\section{Contribution to the literature}

- This study supports research on how students' value-based views affect the science decision-making process in the classroom.

- This study presents evidence into how the initial knowledge, influenced by culture and religion, is organized and becomes the basis for their scientific considerations, especially in dilemma learning settings.

- Findings contribute to the development of science teaching practice, especially on how a decision-making process occurs by a socio-scientific issue-based instruction through integrated STEM education.

This condition provides excellent benefits to teachers in designing and implementing classroom learning (Suratno et al., 2020). Indeed, a student's spontaneous answer to a question been asked is likely to be influenced by many factors. Based on intensive reviews carried out from various works of literature, these factors include initial knowledge, cultural background, beliefs/religions, and student gender (Aguiar et al., 2010; Haug \& Ødegaard, 2015). In this study, they were summarized into two major factors, namely worldview and gender. Worldview is briefly described as a central systemization of the reality concepts sourced and rooted in the value system prevailing in society (Royal, 2002). Meanwhile, Zhang et al. (2017) indicated that gender selectively modulates the influence of anxiety on ambiguous decision-making but not risk decisionmaking. Therefore, this current work was emphasized that the students' worldview perspective and gender potentially contribute greatly to the decision-making process.

STEM education is one of the diversified instructional approaches available to help in scrutinizing this exciting issue (e.g., decision-making process). It is undeniable that in the 21st century, STEM education has great potential in successfully preparing human resources (Chatzopoulos et al., 2019; Dorouka et al., 2020). Therefore, various studies have been carried out to reveal the extraordinary benefits of this approach. Han et al. (2016) stated that STEM education provides better results in increasing academic ability and student learning outcomes. Furthermore, other studies suggest that it may trigger an increase in students' problemsolving abilities (Barrak \& Assal, 2018; Sarican \& Akgunduz, 2018). Integrated STEM education, a particular term under STEM education, positively affects the development of students' complex thought processes because it involves more than one perspective of a scientific discipline (Martín-Páez et al., 2019). Therefore, with integrated STEM education, students are accustomed to convergent and divergent thinking in any favorable learning condition in the decision-making process (Wahono et al., 2020).

Consequently, the great potential in influencing the decision-making process is expected to run well when applied in Indonesia with all the learning characteristics and limitations. Based on the study carried out, integrated STEM education is very suitable to be applied in Asian countries, including Indonesia (Baharin et al., 2018; Chen \& Chang, 2018; Wahono et al., 2020). These studies generally show that its application in Asia had a moderate effect on the outcome of student's learning in the last ten years. This positive effect implies that it is important and very much needed in Asia. However, it also shows that the study and application of integrated STEM education in Indonesia are still lacking.

Although learning with integrated STEM education can make students' decision-making process more comprehensive (Wahono et al., 2020), the study that investigates their worldview relationship toward the decision-making process is still very limited, especially in the science learning setting with integrated STEM education. The study gap and importance would be explored based on the following research questions. Firstly, how is the students' distribution in terms of worldview and gender in the science classes in Indonesia? Secondly, are there significant differences between students' worldview and gender in influencing initial decision-making on controversial issues (GMOs)? Thirdly, how do learning interventions with SSI-STEM instruction affect students' final decision-making? Therefore, to provide answers to these questions, this study explored Indonesian students' worldview perspective on the decision-making process by a socioscientific issue-based instruction through integrated STEM education.

\section{THEORETICAL REVIEW}

\section{Worldview Perspective}

In the classroom learning scope, a student's spontaneous answer to a question been asked is most likely to be influenced by many factors, including initial knowledge, cultural background, religion, and gender (Aguiar et al., 2010; Haug \& Ødegaard, 2015). Therefore, this study focuses on students' cultural background and initial knowledge, specifically summarized in the term "worldview perspective". Specifically, worldview and gender are two important factors that can potentially influence controversial decision-making in humans.

Historically, the term worldview has its origin in Te Wänanga $i$ te mätauranga, a study specializing in knowledge and its position on the human experience of 
the world (Royal, 2002). This study triggers and raises the worldview study and emphasizes the experiences often discussed daily and are very fundamental to the pure knowledge possessed by a society. Therefore, resulting in some interesting questions have been asked. For example, how are our experiences with this world? Is it possible to gain experience of the world without knowledge? And others. These questions apply to the general public and form the basis of students' mental concepts and philosophies in the classroom, especially in terms of decision-making towards solving complex problems.

Furthermore, Marsden and Henare (2002) stated that the term worldview described the perception of cultural patterns from reality into the concept of what they accept as reality, which includes things that are considered as something actual, possible, including something impossible, and certain. In addition, Royal (2002) stated that a worldview is based on the perception of reality, truth, possibilities, and things that are certain and impossible. This concept forms the worldview of a culture.

Meanwhile, gender is a construct used to define the characteristics and roles expected of individuals based on their biological sex (Awad et al., 2017). A worldview by the differences of students' gender is a foundational belief system or framework that researchers employ to help them develop and summarize knowledge on a topic about human behavior, particularly on students. In addition, Zhang et al. (2017) revealed that gender influences human decision-making but not risk decisionmaking. Moreover, Awad et al. (2017) suggested that a discussion of how these worldviews have been applied to the scientific study of gender follows, describing the three categories often thought to most saliently affect gender: (1) biology, (2) psychology, and (3) culture.

The worldview may be concluded as a central systemization of the real concepts that received approval from every aspect of its culture, including originates and is rooted in the value system prevailing in the society (Marsden \& Henare, 2002; Rice, 2005; Royal, 2002). Therefore, it rests on the culture's heart, touches, interacts, and strongly influences every aspect of it, including the education field. The worldview is broadly divided into three pipelines: indigenous, western, and neutral (Gill, 2002; Hart, 2010; Rice, 2005). Indeed, the Indigenous worldview focuses more on the state of a spiritually oriented society, a system of thinking in a society based on and heavily influenced by beliefs and the spiritual world. Meanwhile, the western worldview tends to have a scientific view and is skeptical of everything. The adherents of this view need strong evidence as a basis for their belief and unbelief about anything. A neutral worldview describes a perspective that does not lead to the two views as mentioned earlier. Therefore, it is very important to know the potential role of these three views on student's conceptual change and decision-making process in the classroom.

\section{Socio-Scientific Issue (SSI) in Science Learning}

The rapid development of science and technology has made the socio-scientific issue (SSI) a challenging and important topic in recent decades. The SSI are complex social issues involving concepts, procedures, and technology, including those closely related to science and its derivatives (Leung, 2021; Sadler et al., 2016). Genetically modified organism (GMO) is one of the most popular topics related to SSI (Dowson \& Venville, 2013; Subiantoro, 2017). In recent decades, a study in the science education field has discovered the great benefits of SSI in honing students' inquiry skills regarding science and their actual life experiences (Sadler et al., 2016; Topcu et al., 2010). Therefore, it is undeniable that these characteristics make SSI a vital part of the science learning world these days.

Furthermore, many studies have revealed the advantages of SSI on the thinking and opinion aspects development in science learning. Venville and Dowson (2010) stated that students taught with the SSI topic showed better learning compared to the control class. In this study, the SSI topic used relates to genetic technology. In addition, it was proven by Dowson and Venville (2013) that learning with SSI improves the argumentative skills and informal opinion capacities of the students. Another study carried out by Wu and Tsai (2007) also revealed the role of SSI in learning. The study was proven that students in learning with SSI, especially in the opinion process, tend to be trained using various perspectives and many of them have been honed in terms of evidence-based decision-making abilities. A study that examined teachers' perceptions of learning with the SSI topic revealed that learning discussed SSI is valuable to students (Byford et al., 2009). This value is the students' social development, open-mindedness, broad-minded, and trained in good decision-making processes. Therefore, it may be stated that SSI is a very potential learning topic in developing social values and thinking skills, including students' decision-making processes in the classroom.

\section{Integrated STEM Education}

Lately, STEM (science, technology, engineering, mathematics) education has been developing very rapidly in all parts of the world. This development comprises of many things, one of which is the definition. The simplest definition of STEM education is the education or teaching in one of the four STEM fields of study in science, technology, engineering, and mathematics (Bybee, 2013). A rather broad definition states that STEM education is a learning approach that involves integrated science, technology, engineering, and mathematics on certain topics (Baran et al., 2016; 
Bybee, 2013). The current definition states that STEM education is a learning innovation applied in solving real-world problems characterized by a hands-on activity, which implements several disciplines or skills and hones critical thinking skills, problem-solving, adaptability, and students' collaborative learning (Martín-Páez et al., 2019; Wahono et al., 2020). The last two definitions are more commonly known as integrated STEM education. Therefore, in this study, this definition is adopted as the main reference.

Numerous studies have proven the benefits of integrated STEM education in the classroom. One of the promising benefits is its potential to hone students' opinions and decision-making skills (Suratno et al., 2020). Integrated STEM education positively affects the students' thinking development processes because it involves more than one perspective of a scientific discipline (Martín-Páez et al., 2019). Students are accustomed to convergent and divergent thinking in learning conditions that have been set with integrated STEM education. Therefore, it is undeniable that integrated STEM education plays a major role in attracting students' interest in learning and improving their learning outcomes (Vlasopoulou et al., 2021; Wahono et al., 2020) and may also be a powerful tool in helping complicated decision-making processes for students.

Therefore, it may be stated that SSI and integrated STEM education are compatible and complementary. This assertion is because SSI prepares students to practice facing real-world problems (Sadler, 2009). It is a training context for students to develop abilities and skills in preparing themselves to be active in society. This significant open context is appropriate if it is filled with an approach based on real-world problems such as those that characterize integrated STEM education. Integrated STEM education which also emphasizes the development of critical thinking, creative thinking, problem-solving and collaborative learning (Suratno et al., 2020; Wahono et al, 2020), is in line with the general objectives obtained by SSI learning.

However, other advantages possessed by integrated STEM education will be maximized if other approaches or learning models are used during its implementation (Wahono et al., 2020). The 6E learning model (engage, explore, explain, engineering, enrich, and evaluate) is one of the latest learning models with great potential and is created explicitly by researchers to accommodate integrated STEM education (Chung et al., 2018). This model makes learning more comprehensive, directed, purposeful and further strengthens the $\mathrm{T}$ and $\mathrm{E}$ roles of STEM (Burke, 2014). Therefore, the integration of SSI with STEM-6E in a curriculum or instruction has the potential to strengthen one another and easily achieve the desired learning effectiveness. The curriculum or integrated learning model is expected to be a tool in achieving other major goals, including discovering the vital role of the worldview perspective in the scientific decision-making process of students in the classroom.

\section{METHOD}

\section{Study Procedure}

This work is a pre-experimental design with two collective groups, pretest and posttest, a quasiexperimental study design. However, it started with an educational study design. Shortly, this current study is a curriculum development and implementation. In terms of the study approach, this current work performed an inductive research approach. The study aimed to discover the central role of the worldview perspective on students' decision-making process in learning socioscientific issues through integrated STEM education.

The development of instruments preceded this study as a basis and tool in achieving the final objectives. In particular, the first target in this study was the development of curriculum tools and SSI-based instruction through integrated STEM education learning models. The developed curriculum is specific to IX grade in science subjects, on the biotechnology topic, especially on genetically modified organisms (GMO). Furthermore, four class groups were randomly selected from two different junior high schools as the population and study sample. The two selected schools have relatively the same quality. Therefore, the study procedure generally begins with developing learning curriculum tools and valid data collection instruments and ends with a pre-experimental study with two collective groups, namely pre-test and post-test.

\section{Development of SSI learning curriculum-based instruction through integrated STEM education}

In this study, the first stage is to develop all the instruments needed to explore the role of the worldview perspective in the student's decision-making process by learning socio-scientific issues through integrated STEM education. The learning curriculum tools developed specifically include the STEM-6E model-based curriculum or SSI module, lesson plan, and assessment instruments via Cloud Classroom (CCR).

Specifically, we used the ADDIE (Analysis, Design, Development, Implementation, and Evaluation) development model evaluation (Gustafson \& Branch, 2002). The analysis stage involves gathering information in the outline to determine the problems faced and understand their origin. In designing a curriculum or SSI STEM-6E learning model, a problem is a gap between the conditions that occurred and the desired ideal state. The desired ideal condition is the existence of a curriculum or SSI learning model based on integrated STEM education, which aligns with the Indonesian students' characteristics (Table 1). 
Table 1. Integrated STEM-6E instruction based on socio-scientific issue

\begin{tabular}{ll}
\hline 6E Learning Model & Curriculum Purposes* \\
\hline Engage & $\begin{array}{l}\text { Raise student interest and get them personally involved in the } \\
\text { lesson of socio-scientific issues, e.g., genetically modified } \\
\text { organisms, while pre-assessing prior understanding. }\end{array}$ \\
Explore & $\begin{array}{l}\text { Provide students with the opportunity to engage physically } \\
\text { and mentally with the topic being studied as well as to } \\
\text { construct their own understanding of the topic of GMOs. }\end{array}$
\end{tabular}

Explain Allow students a chance to explain and refine what they have learned so far as well as determine what the meaning of GMO and how a scientist modify organisms.

Engineering The step which is gives a significant opportunity for students to develop a depth of understanding about the GMO by applying concepts, practices, and attitudes. They use concepts learned about the natural world and apply them to the handmade (designed) world.

Enrich This step provides students a more in-depth exploring what they have learned and transferring concepts of genetic modify to problems that are more complex situations.

Evaluate Both students and teachers determine how much learning and understanding have taken place.
Integrated STEM Characteristics

Real-world problems or issues

Hone conceptual understanding

Integrate on at least two fields of science, technology, engineering and mathematics

Hands-on activity, collaborative learning, problem-solving, design thinking skill

Development of critical thinking, creative thinking, problem-solving, decision making

Influence students' learning outcomes

Note*: the curriculum purpose is the 6E learning model goal modified from Burke (2014)

The Design is a stage of learning how to plan in the form of a solution development blueprint. In contrast, the development refers to creating real solutions through a series of SSI curriculum prototypes based on integrated STEM education, where a formative assessment informs it. Implementation means "going live" on these problems, using it in the target context and the actual target audience. Meanwhile, evaluation is a fundamental characteristic of a systematic approach to solving a problem. The formative evaluation seeks information on how to improve the quality of the designed model or curriculum. Conversely, summative evaluation determines the general feasibility or practical level of the model in the expected context.

In detail, the $6 \mathrm{E}$ learning byDeSIGNTM model as the basis for the developed curriculum application is a learning model which was deliberately created to accommodate integrated STEM education. This model emphasizes the "engineering" function in its stages and simultaneously becomes a key feature of integrated STEM education. The integration model developed focuses on GMO issues. In this study, engineering the body or body parts of organisms in living things is an important issue, while the main criteria are curriculum settings and learning models, which provide students with great opportunities to develop their ability to express their opinions and make decisions.

Furthermore, the CCR is an online platform instrument used to record the activities of all students, including pre-test and post-test during the study. The use of CCR makes it easier for teachers to access and test students in real-time. Here is an instance of the pre-test and post-test question: do you agree that humans modify other living things for welfare and survival?

Three experts inspected the content design's rationality in analyzing the SSI-based-instruction's validity by the STEM-6E special course. Indeed, the average expert approval was $86.7 \%$, which is considered a high level of agreement. In addition, they reviewed the objectives throughout the curriculum systematically, checked the design, and assessed each question's accuracy to strengthen its overall reliability and reduce errors in subsequent measurements. In terms of pre-and posttest instruments, which also covered the information about the worldview's items, Cronbach's alpha scores sequentially were 0.73 and 0.78 . As a complement, two senior science teachers with master's degrees have also checked the readability and practicality of curriculum instruction. Therefore, validating the worthiness of the instruments used in this study, especially based on these validity and reliability assessment processes.

\section{Implementation of pre-experimental study (quasi- experimental design)}

The main aim of this study is to investigate the role of students' worldview perspective on decision-making through SSI-STEM-based instruction. Samples were obtained from two junior high schools with the appropriate characteristics of the developmental age of students, using integrated STEM education and SSI learning topics. The integrated STEM education fosters and maintains students' creativity, critical thinking and collaborative abilities. Furthermore, the potential ages in fostering their creativity and collaboration were from 13- 
Table 2. Participant of SSI-STEM based instruction

\begin{tabular}{llcc}
\hline School/ Class & Gender & Number & Percentage (\%) \\
\hline School 1/A & Male & 3 & 12.00 \\
School 1/B & Female & 22 & 88.00 \\
& Male & 2 & 07.70 \\
School 2/A & Female & 24 & 92.30 \\
& Male & 7 & 21.87 \\
School 2/B & Female & 27 & 78.13 \\
& Male & 12 & 46.15 \\
Total Participants & Female & 14 & 53.85 \\
\hline
\end{tabular}

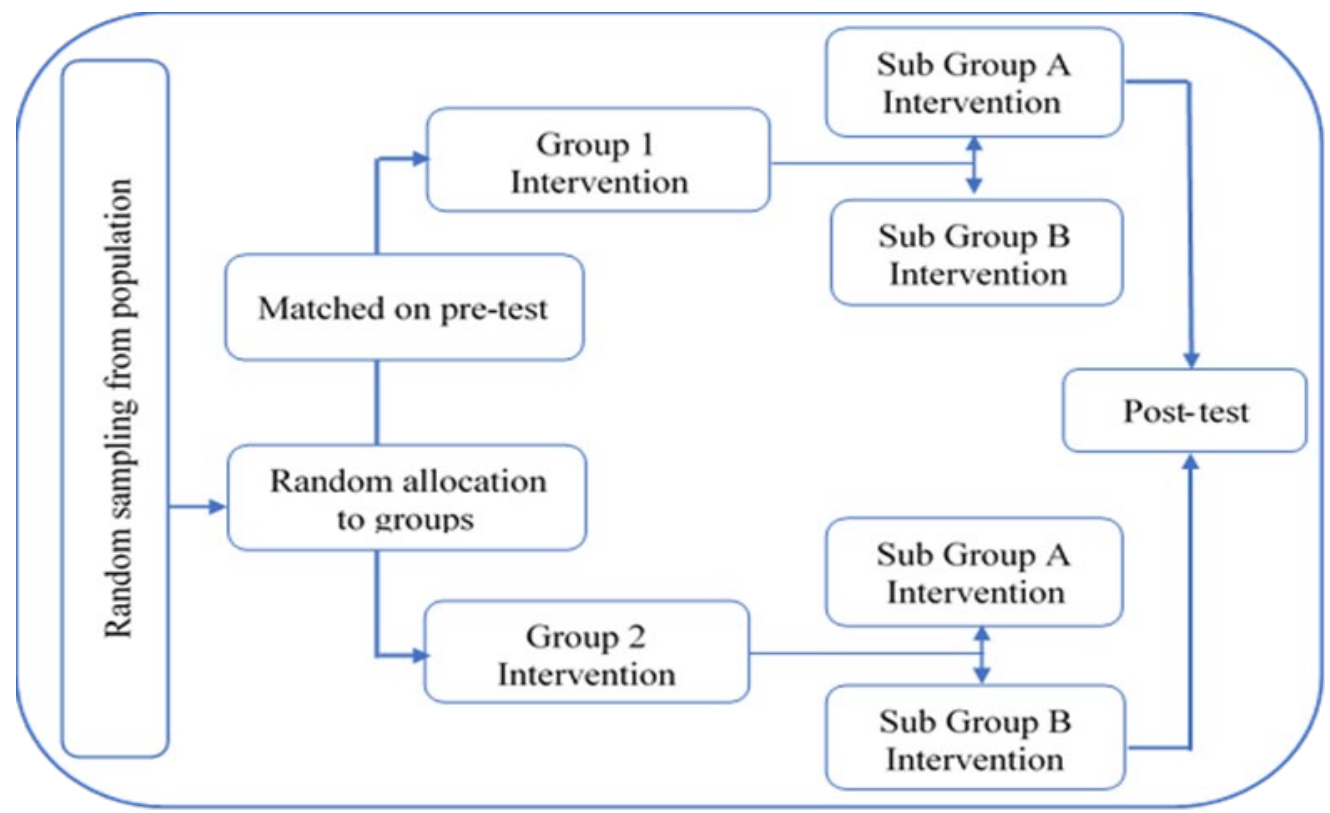

Figure 1. The SSI-STEM based instruction study design

16 because at this age, SSI is an interesting topic due to their high level of curiosity. A complete description of the participants is presented in Table 2.

The SSI-STEM-based instruction curriculum was particularly applied to grade IX (15-16 years old) Junior High School on the topic of Biotechnology (GMO). All the students gave their informed consent before they were included in the study. The intervention instruction was carried out in four different classes for a total of twenty-four hours face to face interaction in four weeks. Schematically, the study design is described as Figure 1.

In this study, several variations of activities and learning materials related to the curriculum were applied. The primary learning techniques or activities are class discussions (37\% of total timespan), group discussions $(18 \%)$, watching videos $(5 \%)$, and some hands-on activities such as designing and modifying a DNA model into recombinant DNA (40\%). In the class's main discussion, the teacher teaches the concepts of biology and biotechnology as the basis for students' knowledge. The scientific concepts used in the STEM-6E curriculum or instrument is mainly about the concept of genetic material and biotechnology (genes, DNA, and genetic engineering technology), with the main topic of discussion being the socio-scientific (SSI) developing in society, which is about genetically modified organism (GMO). In the Indonesian context, it is taboo to modify living things or their body part. Therefore, in this study, the controversial issue of GMOs becomes an essential topic of discussion.

\section{Framework Analysis}

The main framework in helping for the analysis in this particular study was based on the worldview perspective theory. We divided the worldview perspective into three pipelines: indigenous, western, and neutral (Gill, 2002; Hart, 2010; Rice, 2005). Furthermore, all of the study data obtained consisted of participant demographics, and the changes in student decision-making processes were analyzed based on this particular framework. The framework detail's description shows in Table 3.

\section{Data Collection and Analysis}

Generally, in this study, data collection is assisted by the online Cloud Classroom (CCR) platform. The data 
Table 3. The worldview perspective framework

\begin{tabular}{|c|c|}
\hline Worldview Perspectives & Descriptions \\
\hline Indigenous & $\begin{array}{l}\text { - Focused more towards the state of a spiritually oriented society } \\
\text { - A system of thinking in a society which is based on and heavily influenced by beliefs and } \\
\text { the spiritual world } \\
\text { - Example: I believed that God is running the world }\end{array}$ \\
\hline Western & $\begin{array}{l}\text { - Tends to have a scientific view } \\
\text { - } \quad \text { Skeptical of everything } \\
\text { - The adherents of this view need strong evidence as a basis for their believe and unbelief } \\
\text { about anything } \\
\text { - Example: I believed that the world is running by itself }\end{array}$ \\
\hline Neutral & $\begin{array}{l}\text { - A perspective that does not lead to the two aforementioned views } \\
\text { - } \quad \text { Example: I am not sure. Perhaps, those views are valid }\end{array}$ \\
\hline
\end{tabular}

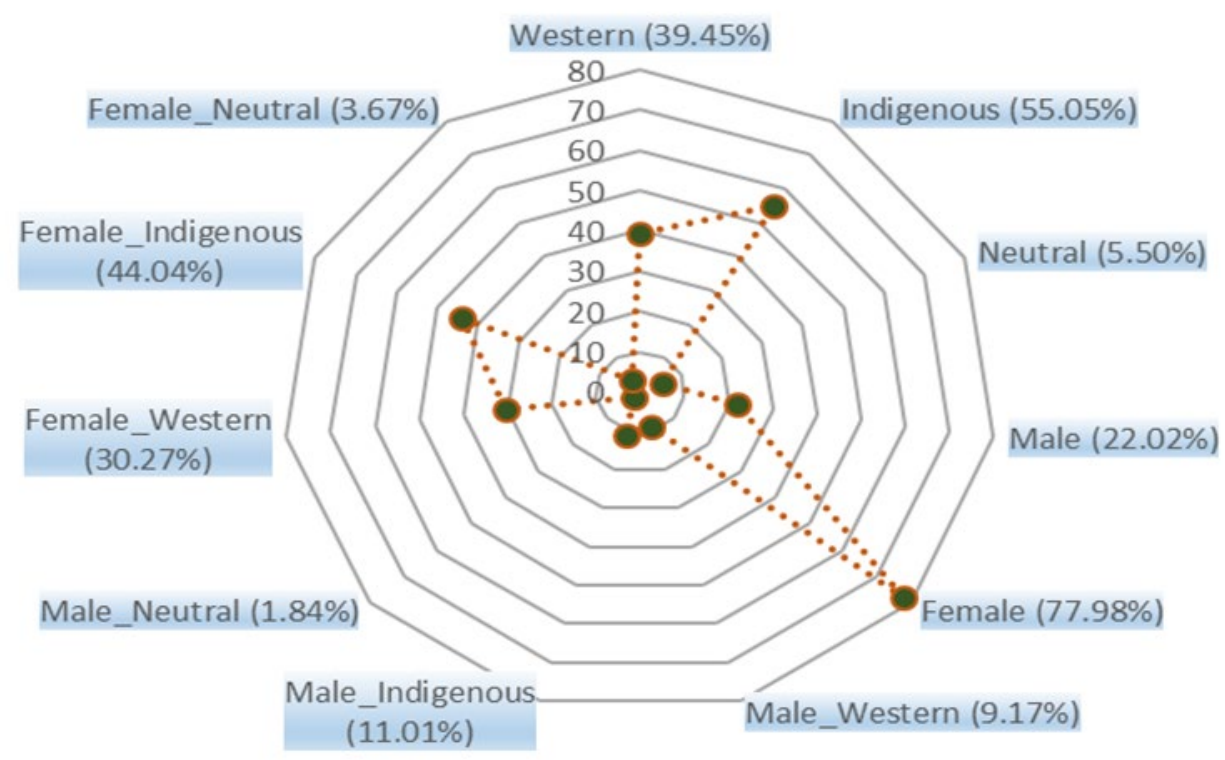

Figure 2. Distribution of students based on their worldview, gender and its interaction

comes from pretest and posttest questions, including formative assessments during learning. Indeed, the preexperimental study data were analyzed using Statistical Product and Service Solutions (SPSS) version 23. In particular, the study data obtained consisted of participant demographics and the changes in student decision-making processes. Descriptive data analysis was used to access students' demographic data, including the distribution of worldview perspectives, gender, and the interaction between worldviews and gender. Furthermore, data on changes in student decision-making processes were analyzed using nonparametric inferential statistics, which is the chi-square test.

\section{RESULTS}

\section{Descriptive Result of Student Worldview and Gender}

Worldview and gender are two important factors that influence controversial decision-making. Several questions have been given to students to test whether they possess a tendency to have western, indigenous or neutral views. The answers provided by these students became the main data to be analyzed quantitatively and qualitatively in this study. Figure 2 illustrates the distribution of data obtained during the study. In addition, it shows the interaction between worldview variables and student gender.

Figure 2 describes three different components, namely worldview, gender, and worldview interactions. These three components are important information that has the potential to influence decision-making and the success of students' learning in class. Furthermore, this data is available to answer the first study question regarding the distribution of students in terms of world views and gender in the case of science classes in Indonesia.

From a worldview point, there are striking differences in the distribution of students between Western, Indigenous, and Neutral. The indigenous perspective shows the highest number of participants $(55.05 \%)$, followed by western orientation in second place $(39.45 \%)$ and finally students with a neutral view 


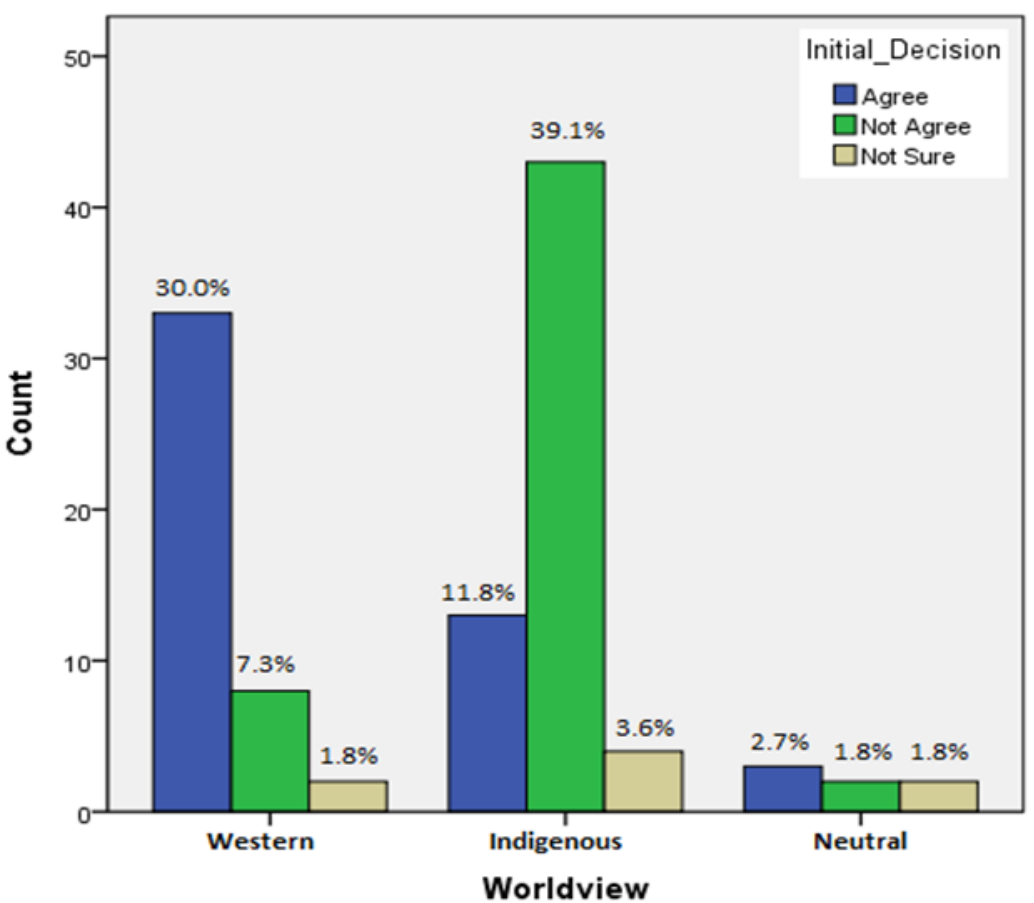

Figure 3. The initial decision of students based on worldview perspective

(5.50\%). This data indicates that Indonesian students' beliefs and initial knowledge towards life, the world, and its contents are quite diverse. Furthermore, in the interaction between gender and world views, it is observed that there are variations in the number of participants, with female indigenes been the dominant participants. Conversely, the male neutral group had the least number of participants.

\section{The Role of Worldview and Gender to Students' Initial Decision}

A controversial question has been raised to investigate the role of worldview and gender in students' initial decisions. This initial decision is essential to understand better the potential role of learning with the integrated STEM education-based socio-scientific issues. The question, which reads "do you agree that humans modify other living things for welfare and survival?" is deliberately made for several reasons and is in accordance with the context and purpose. From a religious and cultural perspective, it is taboo to modify living things or their body parts in Indonesia. Therefore, this question becomes controversial and is able to reveal the relationship between worldview and gender in the initial decisions that students have to make.

Figure 3 describes the different patterns between western, indigenous and neutral perspectives. In particular, most students with a western view (30\%) had no problem with humans modifying living things or other organisms. Only a small proportion $(7.3 \%+1.8 \%)$ of the total participants with western views disagreed or did not believe that humans were able to or had the right to modify organisms or their body parts. This indicated that students with western-oriented view, tended to use logical thinking in controversial decision making.

A different pattern was shown by students with an indigenous view, where most of them (39.1\%) objected that humans were able or had the right to modify other creatures for any reason. This number accounted for the largest number of all participants. Conversely, $11.8 \%$ of participants in this view agreed that humans were able to modify other creatures for reasons of human wellbeing and survival. However, unique data emerged from this perspective, namely $3.6 \%$ of students felt doubtful about making this decision. The number of students that doubted this perspective was quite large when compared to students that had previous world views.

Participants with neutral view had fairly even distribution of opinions on the questions given. However, the proportion of students with the opinion that modifying living things was important and that it may be done, were slightly larger compared to students that disagreed and were still doubtful. Fairly even distribution among participants that appear neutral strengthens the evidence that the questions given make students feel a dilemma in choosing between things that are rational and what they believe.

Some interesting things were also discovered based on data on gender roles in students' initial decision making (Figure 4). First, male students $(11.9 \%)$ tends to agree that humans modify other living things for reasons of their welfare and survival however, the difference is not very significant (only 1.8\%). Conversely, female students tended to disagree with the ideas presented 


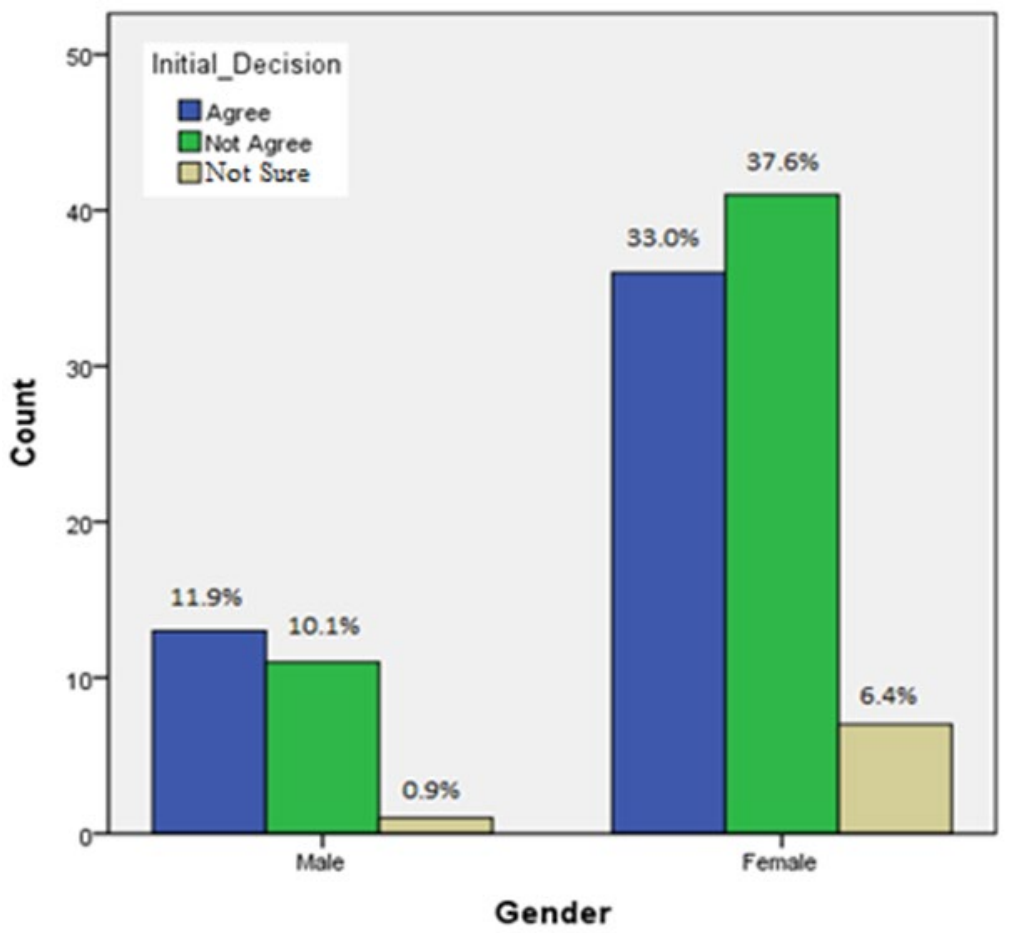

Figure 4. The initial decision of students based on gender

Table 4. Chi-square analysis of the worldview and gender

\begin{tabular}{lcccc}
\hline Variable & $\mathrm{N}$ & Pearson Chi-Square & Contingency Coefficient & Asymp. Sig. (2-sided) \\
\hline Worldview & 109 & 37.100 & .502 & $<.001$ \\
Gender & 109 & .945 & .093 & .624 \\
\hline
\end{tabular}

(37.6\%) although, the number of students that agreed was also quite a lot (33.0\%).

Another interesting thing was that there were quite different patterns between students that felt inferior in answering the questions given. Female students had a fairly large distribution $(6.4 \%)$ when compared to male students $(0.9 \%)$. Therefore, indirectly, there were differences in the pattern of initial decision making between male and female students in controversial situations. Furthermore, further analysis was carried out to determine if there were significant differences between the variables studied. Table 4 shows whether there are significant differences in initial decisions among students based on different types of world views (western, indigenous, neutral) and gender (male and female).

The fact revealed from this analysis is the difference in the pattern of significance in the worldview and gender variables. Specifically, there were significant differences in students' initial decisions based on a worldview perspective (contingency coefficient $=0.0502$, $p=<.001$ ). This difference occurred for both students that saw western vs indigenous, western vs neutral and indigenous vs neutral. Conversely, there was no significant difference in the initial decision based on gender (contingency coefficient $=0.093 ; p=0.624$ ) .

\section{Making Decision through SSI-STEM Instruction}

The environmental context of Indonesia and its participants which are very thick with cultural and religious influences made many topics of science and technology learning warm to discuss. In this study, socio-scientific issue-based Instruction through integrated STEM education was applied. This final goal was for researchers that wanted to know whether learning interventions with integrated STEM learning on the topic of the socio-scientific issue (SSI) had an effect on students' final decision making. Figure 5 illustrates the dynamics of changing student decisions based on a worldview perspective. Meanwhile, Figure 6 illustrates the change in student decisions based on gender. The changes that occur are evidence of the central role of integrated STEM learning on socio-scientific issue-based learning topics.

There were several descriptive changes in students' decisions with the same question after the intervention with STEM-SSI instruction. On the western view, the number of students that agreed that humans were able to change other living things decreased by $7.1 \%$ (30$22.9 \%$ ). The same thing happened to students that rejected the idea, they decreased by $1.8 \%$ (7.3-5.5\%). However, this was different from students that were not sure of the previous answer. In this group, there was a significant increase in the number of total participants by 

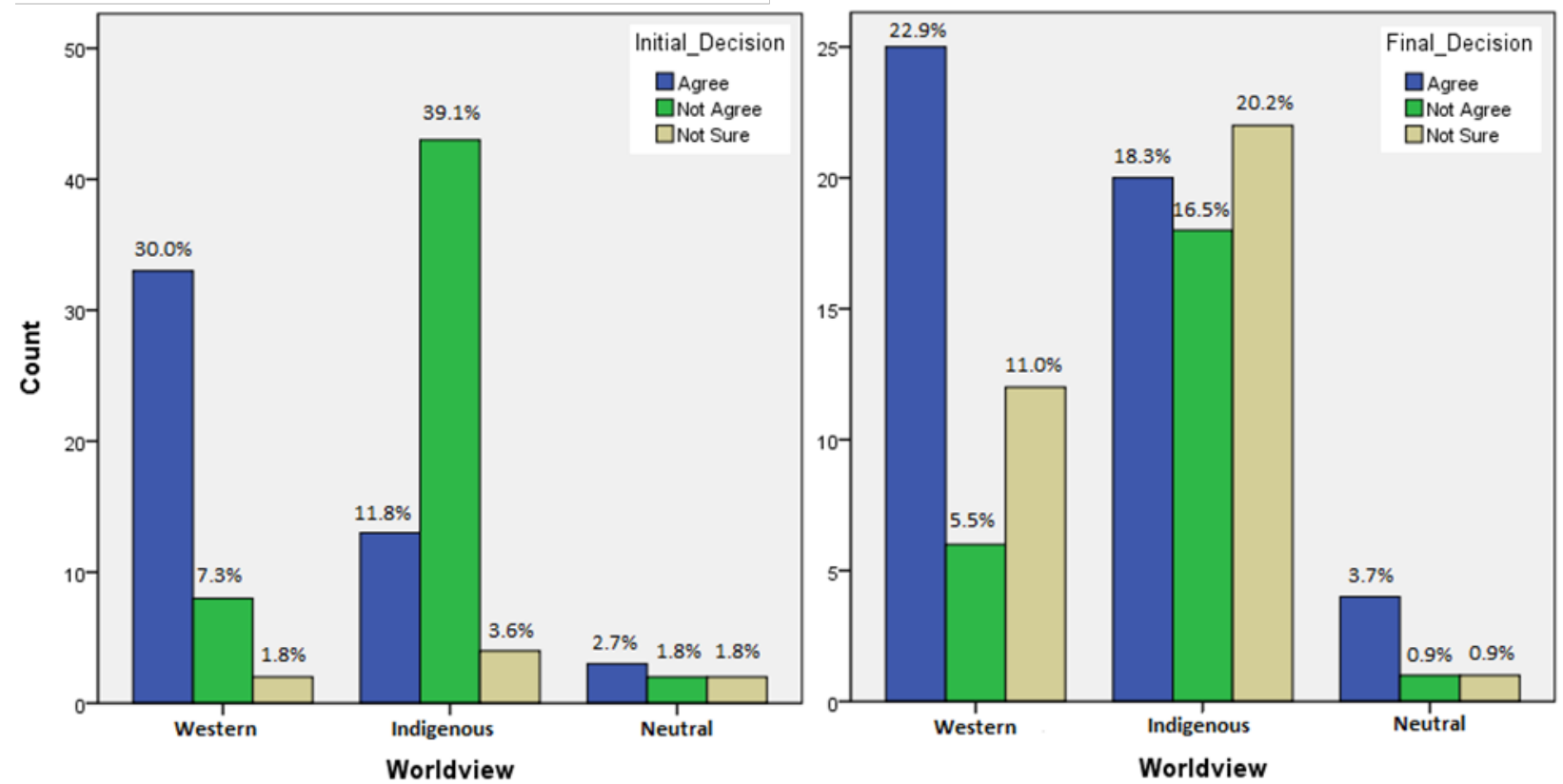

Figure 5. The changing of students' decision based on worldview perspective
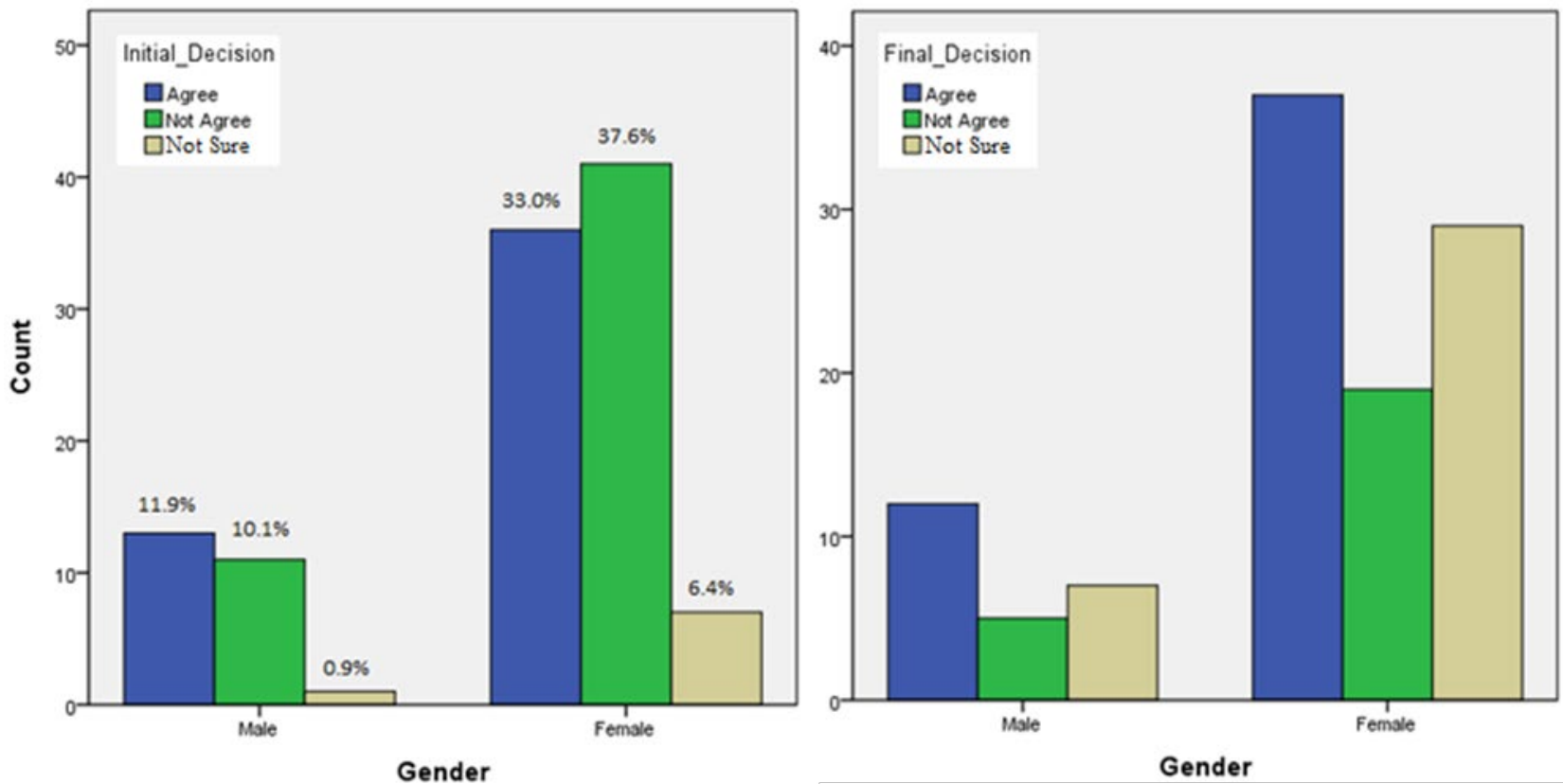

Figure 6. The changing of students' decision based on gender

$10.2 \%(20.2-1.8 \%)$. Therefore, the biggest change after the intervention for students with a western view was in the group without a strong opinion ("not sure" answers).

A different pattern is shown by the groups of students with an indigenous view, with significant dynamics of change. Students that were in agreement with the idea of modifying living things through GMOs increased significantly by $6.5 \%$ (18.3-11.8\%). Meanwhile, participants that rejected the idea fell significantly by $22.6 \%(39.1-16.5 \%)$. The group of students that were unsure of the answer had the same pattern as the group of students with a western view, i.e., an increase of $16.6 \%$ (20.2-3.6\%). Therefore, the biggest change after the intervention of students with an indigenous view was the decrease in the number of groups that rejected the idea of modifying living things through GMO technology.

It is important to note the change in decision by participants of the neutral group based on this worldview perspective. The number of students that were initially in agreement with the idea of the modification of living things increased by $1 \%$ (3.7-2.7\%). Conversely, there was a decrease in the number of students in the group that were in disagreement and the group of students that were in doubt by .9\% (1.8-.9\%). However, the changes that occur in this group of students with a neutral view are not clearly seen because of the limited sample size. 
Table 5. Chi-square analysis of the students' decision changing

\begin{tabular}{|c|c|c|c|c|c|c|c|}
\hline Variable & Pattern & $\begin{array}{c}\text { Initial } \\
\text { Decision }\end{array}$ & Final Decision & $\mathrm{df}$ & $\begin{array}{c}\text { Pearson Chi- } \\
\text { Square }\end{array}$ & $\begin{array}{l}\text { Asymp. Sig. } \\
\text { (2-sided) }\end{array}$ & $\begin{array}{c}\text { Contingency } \\
\text { Coefficient }\end{array}$ \\
\hline \multirow{9}{*}{ Worldview } & $W^{*} A$ & 33 & 25 & \multirow{9}{*}{8} & \multirow{9}{*}{34.058} & \multirow{9}{*}{$<.001$} & \multirow{9}{*}{.368} \\
\hline & $W^{*} \mathrm{NA}$ & 8 & 6 & & & & \\
\hline & $\mathrm{W}^{*} \mathrm{NS}$ & 2 & 12 & & & & \\
\hline & $\mathrm{I}^{*} \mathrm{~A}$ & 13 & 20 & & & & \\
\hline & $\mathrm{I}^{*} \mathrm{NA}$ & 43 & 18 & & & & \\
\hline & $\mathrm{I}^{*} \mathrm{NS}$ & 4 & 22 & & & & \\
\hline & $\mathrm{N}^{*} \mathrm{~A}$ & 2 & 4 & & & & \\
\hline & $\mathrm{N}^{*} \mathrm{NA}$ & 2 & 1 & & & & \\
\hline & $\mathrm{N}^{*} \mathrm{NS}$ & 2 & 1 & & & & \\
\hline \multirow{6}{*}{ Gender } & $\mathrm{M}^{*} \mathrm{~A}$ & 33 & 25 & \multirow{6}{*}{5} & \multirow{6}{*}{28.315} & \multirow{6}{*}{$<.001$} & \multirow{6}{*}{.339} \\
\hline & $\mathrm{M}^{*} \mathrm{NA}$ & 8 & 6 & & & & \\
\hline & $\mathrm{M}^{*} \mathrm{NS}$ & 2 & 12 & & & & \\
\hline & $\mathrm{F}^{*} \mathrm{~A}$ & 13 & 20 & & & & \\
\hline & $\mathrm{F}^{*} \mathrm{NA}$ & 43 & 18 & & & & \\
\hline & $\mathrm{F}^{*} \mathrm{NS}$ & 4 & 22 & & & & \\
\hline
\end{tabular}

Note: $W=W e s t e r n, I=I n d i g e n o u s, N=$ Neutral, $M=$ Male, F=Female, $A=$ Agree, $N A=$ Not Agree, NS= Not Sure

Another thing that is shown from the analysis results is the dynamics of change from the initial decision to a final decision based on the gender of the students (Figure 6). The results show that there is a prominent pattern of change in male students. The number of male students that were in disagreement reduced by $5.5 \%$ (10.1-4.6\%) after the intervention from the STEM-SSI instruction. Conversely, students that did not have a definite answer ("not sure" answer) increased by 5.5\% (6.4-.9\%), but there was no clear change in the number of male students that were in agreement with the idea of modifying living things in GMO technology.

The dynamics that are very similar to the male student groups are shown based on the analysis results of changes in female students' decisions. There was a decrease in the number of students by $20.2 \%$ (37.6-17.4\%) after the intervention, especially in the group of students that rejected the idea of GMOs. In addition, for students without a strong opinion ("not sure" answer), the same as for the male group, there was a significant increase $(20.2 \%)$ in the decision of the student after the intervention. Furthermore, the number of students that were in agreement with the idea did not show a significant change $(0.9 \%)$, nor did the male student group. Further analysis of the descriptive data is shown in Table 5, using the following chi-square test aims to determine whether the data in question is significantly different or just a coincidence.

Table 5 shows the results of the chi-square analysis of decision changes on worldview and gender variables. This result is an accumulation of many interaction patterns as shown in the "patterns" column. Pearson's chi-square value showed a significant difference $(\chi 2=$ $34.05, p=<.001)$ in the worldview variable. In addition, with the gender variable, a significant difference $(\chi 2=$ $28.31, p=<.001)$ was discovered regarding changes in student decisions before and after the intervention.
Therefore, it may be concluded that the STEM-SSI Instruction learning intervention provides significant dynamics of change to students based on the worldview perspective and gender differences.

\section{DISCUSSION}

\section{Students' Worldview Influences Their Viewing on Socio-Scientific Issue}

Different view patterns were revealed based on the initial decision from the students' worldview perspective. In particular, students with a western view generally had no problem with humans modifying living things or other organisms. Conversely, students with the original view were against humans modifying other creatures for any reason. This fact is not different from the researchers' expectations extracted from the literature review on individual characteristics based on a worldview perspective (Aguiar et al., 2010; Haug \& Ødegaard, 2015; Royal, 2002). Indeed, individuals with a Western worldview tend to be scientific and skeptical. It takes solid and tangible evidence as the basis for their belief, which states that individuals with an indigenous view are spiritually oriented, and their belief system is based on the spiritual world (Royal, 2002). Therefore, one of the crucial characteristics in the success of learning with the theme of controversial issues, which is the implication of these results, is that the teacher should pay attention to the heterogeneity of the students' background system basis. Furthermore, the basic system may be obtained from simple questions asked by the teacher at the beginning of the lesson.

Participants with a neutral view have a fairly even distribution of opinions on the questions given. This result makes sense because students without western trends or indigenous viewpoints do not have a solid belief foundation. They will undoubtedly spread more 
evenly depending on the extent of the information at their disposal. Furthermore, they are unsure of the decisions or opinions they make. As facilitators, teachers should be able to detect this kind of student. Students with a neutral view easily accept new information compared to those that already have strong beliefs and knowledge embedded in their minds (Gill, 2002; Hart, 2010; Rice, 2005). The teacher's role is also crucial because it becomes the basis for their future thinking system if they discover the same phenomenon. Therefore, on the contemporary models of teaching/learning, the student's prior knowledge, attitudes, and background need to be known, honored, and engaged during the various phases of instruction. Students with very strongly anchored views, understandings, or misconceptions need special consideration to initiate their re-examination of the prior positions.

Furthermore, there is a significant difference in the initial decisions of the students based on the world view perspective, but there is no significant difference in the initial decisions based on gender. These results provide the fact that in learning with the theme of socio-scientific problems, the world view perspective is more dominant in influencing students' decisions compared to their gender. This result is quite difference with the study propose by Asli et al. (2021) that revealed a significant difference between boys and girls, girls had more decision-making ability than boys, regarding a sea turtle conservation issue. One practical implication drawn based on these facts is the consideration taken in forming groups of students in the classroom. During learning with thick controversial issues, teachers should focus more on a worldview perspective rather than on gender which informs student learning and discussion groups. In fact, sometimes, gender should also be taken into account with the aim of equality and other goals.

\section{STEM-SSI Instruction Has a Significant Role on Students' Decision-Making Process}

The group without strong opinions ("not sure "answer) is the most significant change after SSI-based learning interventions through integrated STEM education in the students with a westernized view. Meanwhile, the most significant change after the intervention of indigenous students was the decrease in the number of groups that rejected the idea of modifying living things through GMO technology.

These two different views reinforced the evidence that the fundamental sources of students in making decisions are closely related to the mental perceptions that have been attached to their minds. This opinion is in accordance with the study, which states that all human physical or verbal activities are strongly influenced by their beliefs (Duit \& Treagust, 2003; Vosniadou, 2007). However, verbal decisions or physical activity that occurs may differ from what they believe or believed. This condition occurs when other factors make them unable to freely express what they believe, such as fear, limited opportunities, or because the rewards they receive are more tantalizing compared to the limitations of their beliefs (Vosniadou, 2007). In the context of the GMO that has been implemented, students may feel afraid to oppose their religious belief that humans cannot change the creation of other Gods, especially students who have an indigenous view. It will be tough to change mental perceptions that have been inherent for a long time unless there is strong evidence or a very significant reason (Leung, 2021). Furthermore, Duit and Treagust (2003) stated that another critical factor in conceptual change is the frequent use of new concepts that make sense to students. Therefore, SSI-based learning through integrated STEM education interventions has proven to be effective in increasing the frequency of the use of sensible concepts for students, which simultaneously has an impact on changing the mental perception of students.

Furthermore, another area of discussion is the existence of the same exciting patterns that change the students' final decisions based on worldview and gender perspectives. Intervention with SSI-based instruction through integrated STEM education provides a dynamic of significant changes in the final decisions of the students based on these two aspects. These results prove that integrated STEM education has great potential in changing the decisions of science students in the classroom. When approached with integrated STEM education, factors such as worldview and student gender are not major challenges for teachers when teaching science learning which is a controversial topic. Therefore, the practical implications that teachers may take from this study are that they do not need to worry too much about the differences in the backgrounds of students in the classroom, as long as they can effectively and correctly process learning. One of them is by choosing the right learning approach with the characteristics of students' conceptual content and cognitive development.

\section{CONCLUSION}

This study revealed the central role of a worldview perspective on science students' decision-making processes in controversial learning contexts. Indeed, this work concludes that there is a different perspective pattern based on the worldview perspective on students' initial decisions. Likewise, this work explicitly reveals a significant difference in students' initial decisions based on worldview. In contrast, there was no significant difference in the initial decision based on gender. Furthermore, interventions with socio-scientific issues (SSI) based instruction through integrated STEM education provided significant dynamics of change in 
the final science decision made by the students based on a worldview perspective and gender. Moreover, this current study suggests that the teacher's role in selecting and determining the right instructional strategy for learning, such as SSI-based instruction through integrated STEM education, determines and influences students' thought patterns and decision-making processes. However, this study faced several limitations, one of which was the scope that participants were only in certain regions in Indonesia. Logically, in terms of geography and sample size, this study does not represent Indonesia's population as a whole. However, it provides a simple example that may generally represent the cultural aspects and learning settings that occur daily. Furthermore, intending to strengthen the results, this study discovered that similar studies were urgently needed in Indonesia and other countries, especially those that differ significantly in culture and formal education settings. This result may also be the basis for further studies, such as the extent to which students' worldview perspectives play a role in the scientific decision-making process in the context of nonSSI learning with the same approach, namely through integrated STEM education learning. Finally, it also makes an indispensable contribution to developing a worldwide body of knowledge in science teaching practice.

Author contributions: All authors have sufficiently contributed to the study, and agreed with the results and conclusions.

Funding: Authors gratefully acknowledge funding from the University of Jember's internal funds for the post-doctor project: Grant No. 15732/UN25/LT/2020.

Declaration of interest: No conflict of interest is declared by authors.

\section{REFERENCES}

Aguiar, O. G., Mortimer, E. F., \& Scott, P. (2010). Learning from and responding to students' questions: The authoritative and dialogic tension. Journal of Research in Science Teaching, 47(2), 174-193. https://doi.org/10.1002/tea.20315

Asli, S., Kortam, N., Algamal, S., Sheme, N., \& Hugerat, M. (2021). The decision-making ability of 10th grade students in an Arab community in Israel to preserve sea turtles. EURASIA Journal of Mathematics, Science and Technology Education, 17(3), em1948. https://doi.org/10.29333/ejmste/9758

Awad, M., Rayfield, N., \& Miville, M. L. (2017). Worldviews and gender research. In K. L. Nadal (Ed), The SAGE encyclopedia of psychology and gender. SAGE Publications, Inc.

Baharin, N., Kamarudin, N., \& Manaf, U. K. A. (2018). Integrating STEM education approach in enhancing higher order thinking skills. International Journal of Academic Research in Business and Social Sciences, 8(7), 810-822. https://doi.org/ 10.6007/IJARBSS/v8-i7/ 4421
Barak, M., \& Assal, M. (2018). Robotics and STEM learning: Students' achievements in assignments according to the P3 Task Taxonomy-practice, problem solving, and projects. International Journal of Technology and Design Education, 28(1), 121-144. https:/ / doi.org/10.1007/s10798-016-9385-9

Baran, E., Bilici, S. C., Mesutoglu, C., \& Ocak, C. (2016). Moving STEM beyond schools: Students' perceptions about an out-of-school STEM education program. International Journal of Education in Mathematics Science and Technology, 4(1), 9-19. https:/ / doi.org/10.18404/ijemst.71338

Burke, D. (2014). The ITEEA 6E learning byDeSIGN'TM model, maximizing informed design and inquiry in the integrative STEM classroom. Technology and Engineering Teacher, 73(6), 14-19.

Bybee, R. W. (2013). The case for STEM education: Challenges and opportunities. NSTA Press.

Byford, J., Lennon, S., \& Russell, W. B. (2009). Teaching controversial issues in the social studies: A research study of high school teachers. The Clearing House: A Journal of Educational Strategies, Issues and Ideas, 82(4), 165-170. https://doi.org/10.3200/TCHS.82. 4.165-170

Chatzopoulos, A., Papoutsidakis, M., Kalogiannakis, M., \& Psycharis, S. (2019). Action research implementation in developing an open source and low-cost robotic platform for STEM education. International Journal of Computer Applications, 178(24), 33-46. https://doi.org/10.5120/ ijca2019919039

Chen, Y., \& Chang, C.-C. (2018). The impact of an integrated robotics STEM course with a sailboat topic on high school students' perceptions of integrative STEM, interest, and career orientation. EURASIA Journal of Mathematics, Science and Technology Education, 14(12), 1614. https://doi.org/10.29333/ejmste/94314

Chung, C. C., Lin, C. L., \& Lou, S. J. (2018). Analysis of the learning effectiveness of the STEAM-6E special course-a case study about the creative design of IoT assistant devices for the elderly. Sustainability (Switzerland), 10(9), 3040. https://doi.org/ $10.3390 /$ su10093040

Dawson, V., \& Venville, G. (2013). Introducing high school biology students to argumentation about socioscientific issues. Canadian Journal of Science, Mathematics and Technology Education, 13(4), 356372. https:/ / doi.org/10.1080/14926156.2013.845322

Dorouka, P., Papadakis, St., \& Kalogiannakis, M. (2020). Tablets \& apps for promoting Robotics, Mathematics, STEM Education and Literacy in Early Childhood Education. International Journal of 
Mobile Learning and Organisation, 14(2), 255-274. https:/ / doi.org/10.1504/IJMLO.2020.10026334

Duit, R., \& Treagust, D. (2003). Conceptual change: a powerful framework for improving science teaching and learning. International Journal of Science Education, 25(6), 671-688. https:/ / doi.org/10.1080/09500690305016

Gill, J. H. (2002). Native American worldviews: An introduction. Humanity Press.

Gustafson, K. L. \& Branch, R. M. (2002). Survey of instructional development models (4th ed.). ERIC Clearinghouse on Information \& Technology.

Han, S., Rosli, R., Capraro, M. M., \& Capraro, M. R. (2016). The effect of Science, Technology, Engineering and Mathematics (STEM) ProjectBased Learning (PBL) on students' achievement in four mathematics topics. Journal of Turkish Science Education, 13, 3-29. https://doi.org/10.12973/ tused.10168a

Hart, M. A. (2010). Indigenous worldviews, knowledge, and research: the development of an indigenous research paradigm. Journal of Indigenous Voices in Social Work, 1(1), 1-16.

Haug, Berit S \& Ødegaard, Marianne. (2015). Formative assessment and teachers' sensitivity to student responses. International Journal of Science Education, 37(4), 629-654. https://doi.org/10.1080/09500693. 2014.1003262

Leung, J. S. C. (2021). Shifting the teaching beliefs of preservice science teachers about socioscientific issues in a teacher education course. International Journal of Science and Mathematics Education. https:// doi.org/10.1007/s10763-021-10177-y

Lie, A. (2015). Religious education and character formation: An Indonesian context. Journal of Interdisciplinary Studies, 5(1). https://doi.org/ 10.5840/jis2014261/24

Marsden, R. M., \& Henare, T. A. (2002). Kaitiakitanga: A Definitive Introduction to the Holistic Worldview of the Maori (Unpublished paper).

Martín-Páez, T., Aguilera, D., Perales-Palacios, F. J., \& Vílchez-González, J. M. (2019). What are we talking about when we talk about STEM education? A review of literature. Science Education, 103(4), 799822. https://doi.org/10.1002/ sce.21522

Petousi, V., \& Sifaki, E. (2020). Contextualizing harm in the framework of research misconduct: Findings from a discourse analysis of scientific publications. International Journal of Sustainable Development, 23(34), 149-174, https://doi.org/10.1504/IJSD.2020. 10037655

Rice, B. (2005). Seeing the world with Aboriginal eyes: A four-dimensional perspective on human and non-human values, cultures and relationships on Turtle Island. Aboriginal Issues Press.
Royal. (2002). Indigenous worldviews: A comparative study. Royal Report.

Sadler, T. D. (2009). Situated learning in science education: Socio-scientific issues as contexts for practice. Studies in Science Education, 45(1), 42. https:/ / doi.org/10.1080/03057260802681839

Sadler, T. D., Romine, W. L., \& Topçu, M. S. (2016). Learning science content through socio-scientific issues-based instruction: a multi-level assessment study. International Journal of Science Education, 38(10), 1622-1635. https://doi.org/10.1080/ 09500693.2016.1204481

Sarican, G., \& Akgunduz, D. (2018). The impact of integrated STEM education on academic achievement, reflective thinking skills towards problem solving and permanence in learning in science education. Cypriot Journal of Educational Sciences, 13(1), 94-107. https://doi.org/10.18844/ cjes.v13i1.3322

Subiantoro, A. W. (2017). Promoting Socio-scientific Issuesbased Learning in Biology: Indonesian Students' and Teacher's Perceptions and Students' Informal Reasoning (Doctoral thesis of Science Education). Curtin University.

Suratno, S., Wahono, B., Chang, C.-Y., Retnowati, A., \& Yushardi. (2020). Exploring a direct relationship between students' problem-solving abilities and academic achievement: A STEM education at a coffee plantation area. Journal of Turkish Science Education, 17(2), 211-224. https:/ / doi.org/10.36681 / tused.2020.22

Topcu, M. S., Sadler, T. D., \& Yilmaz-Tuzun, O. (2010). Preservice science teachers' informal reasoning about socioscientific issues: The influence of issue context. International Journal of Science Education, 32(18), 2475-2495. https://doi.org/10.1080/ 09500690903524779

Venville, G. J., \& Dawson, V. M. (2010). The impact of a classroom intervention on Grade 10 students' argumentation skills, informal reasoning, and conceptual understanding of science. Journal of Research in Science Teaching, 47(8), 952-977. https:// doi.org/10.1002/tea.20358

Vlasopoulou, M., Kalogiannakis, M., \& Sifaki, E. (2021). Investigating teachers' attitude and behavioral intentions for the impending integration of STEM education in primary school. In St. Papadakis \& M. Kalogiannakis (Eds.), Handbook of research on using education robotics to facilitate student learning (pp. 235-256). IGI Global. https:/ / doi.org/10.4018/9781-7998-6717-3.ch009

Vosniadou, S. (2007). Conceptual change and education. Human Development, 50, 47-54. https:// doi.org/10.1159/000097684 
Wahono, B., \& Chang, C.-Y. (2019). Assessing teacher's attitude, knowledge, and application (AKA) on STEM: An effort to foster the sustainable development of STEM education. Sustainability, 11(4), 950. https:/ / doi.org/10.3390/su11040950

Wahono, B., Lin, PL. \& Chang, C.-Y. (2020). Evidence of STEM enactment effectiveness in Asian student learning outcomes. International Journal of STEM Education, 7, 36. https://doi.org/10.1186/s40594020-00236-1
Wu, Y.-T., \& Tsai, C-C. (2007). High school students' informal reasoning on a socio-scientific issue: Qualitative and quantitative analyses. International Journal of Science Education, 29(9), 1163-1187. https:/ / doi.org/10.1080/09500690601083375

Zhang, F., Xiao, L., \& Gu, R. (2017). Does gender matter in the relationship between anxiety and decisionmaking? Frontiers in Psychology, 8, 2231. https:/ / doi.org/10.3389/fpsyg.2017.02231

http://www.ejmste.com 